\title{
Cenário da covid-19 no estado do Ceará, Brasil
}

Igor Gomes de Araújo'

Arlandia Cristina Lima Nobre de Morais'

\section{RESUMO}

A covid-19 apresenta relação com a síndrome respiratória aguda causada pelo novo coronavírus, vírus de RNA, possuindo alta capacidade de transmissão. O presente estudo objetivou analisar o cenário da taxa de ocupação de leitos decorrente da covid-19 no estado do Ceará, Brasil. Trata-se de estudo descritivo, de análise do cenário da taxa de ocupação de leitos decorrente da covid-19 no estado do Ceará, Brasil. Ressaltase que muitos dos pacientes aguardam testagem para covid-19. Buscou-se identificar o perfil dos serviços disponíveis na capital, Fortaleza. A coleta dos dados ocorreu no dia 14 de abril de 2020, nos sites IntegraSus e Coe-Covid-19. A atualização do boletim epidemiológico do dia 14 de abril de 2020, apresentou 2.044 casos confirmados, segundo data do início dos sintomas; 1.878 casos novos confirmados, segundo data do resultado do exame, 111 óbitos, 5,43 letalidade, 62 municípios com casos confirmados, 11.954 quantidade de exames e 9.242 casos supeitos. Outros equipamentos de saúde apresentam altas taxas de vagas já em ocupação desde janeiro, antes da chegada do vírus, por demandas de rotina. A maior incidência de internados são do sexo masculino (57,5\%) e entre ambos os sexos, acima de 45 anos. Com concentração do número de casos em Fortaleza, 59 internados e 1.794 casos confirmados da doença, seguido de Caucaia (39 casos), Maracanaú (35 casos) e Aquiraz (30 casos). Pode-se concluir um cenário de preocupação diante de poucos leitos disponíveis, face de um possível colapso com a incidência dos casos mais graves da doença que necessitam de suporte adequado.

Palavras-chave: Covid-19. Coronavírus. Ceará. Diagnóstico situacional. Epidemiologia.

\section{INTRODUÇÃO}

As doenças crônicas não transmissíveis (DCNT), são as principais causas de mortalidade mundial, impactos na qualidade de vida e econômica. Entre elas, doenças do aparelho circulatório, neoplasias, diabetes e doenças respiratórias crônicas. Em Ceará, Brasil, no ano de 2018, o número de óbitos por DCNT foi de 50,6\% [1]. O estado possui 184 municípios e apresentou no último censo realizado, em 2010, 8.452.381 habitantes. A estimativa é que em 2019 este número cresceu para 9.132.078. Ainda do censo de 2010, a população com idade igual ou superior a 60 anos, grupo de risco para a covid-19, 406.718 são do sexo masculino e 502.757 do sexo feminino [2].

A covid-19 apresenta relação com a síndrome respiratória aguda (SARS-CoV-2) causada pelo novo coronavírus, vírus de RNA, possuindo alta capacidade de transmissão [3]. Atualmente possui sete tipos de coronavírus com capacidade em infectar humanos. A Organização Mundial de Saúde (OMS), estimou uma letalidade por covid-19 no Brasil de 3,4\%, semelhante a gripe espanhola (2 a 3\%), maior que a influenza H1N1 $(0,02 \%)$ e gripe sazonal $(0,1 \%)$. Todavia, a maioria dos casos apresentam sintomas leves $(80,9 \%)[4,5]$.

O presente estudo objetivou analisar o cenário da taxa de ocupação de leitos decorrente da covid-19 no estado do Ceará, Brasil.

\section{METODOLOGIA}

Trata-se de estudo descritivo, de análise do cenário da taxa de ocupação de leitos decorrente da covid-19 no estado do Ceará, Brasil. Ressalta-se que muitos dos pacientes aguardam testagem para covid-19. Buscou-se identificar o perfil dos serviços disponíveis na

\footnotetext{
${ }^{1}$ Universidade de Fortaleza, Curso de Farmácia. Av. Washington Soares, 1321, Edson Queiroz, 60811-905, Fortaleza, CE, Brasil. Correspondência para IG ARAÚJO. E-mail: <gomes.igor1996@gmail.com>.

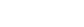

Como citar este artigo / How to cite this article

Araújo IG \& Morais ACLN. Cenário da covid-19 no estado do Ceará, Brasil. InterAm J Med Health 2020;3:e202003015.
} 
capital, Fortaleza. A coleta dos dados ocorreu no dia 14 de abril de 2020, nos sites IntegraSus e Coe-Covid-19.

\section{RESULTADOS}

A atualização do boletim epidemiológico do dia
14 de abril de 2020 (tabela 1), apresentou 2.044 casos confirmados, segundo data do início dos sintomas; 1.878 casos novos confirmados, segundo data do resultado do exame, 111 óbitos, 5,43 letalidade, 62 municípios com casos confirmados, 11.954 quantidade de exames e 9.242 casos suspeitos [6].

Tabela 1. Indicadores de coronavírus no Ceará, boletim epidemiológico atualizado no dia 14 de abril de 2020.

\begin{tabular}{|l|c|}
\hline Casos confirmados, segundo data do início dos sintomas & 2.044 \\
\hline Casos novos confirmados, segundo data do resultado do exame & 1.878 \\
\hline Óbitos & 111 \\
\hline Letalidade & 5,43 \\
\hline Municípios com casos confirmados & 62 \\
\hline Quantidade de exames & 11.954 \\
\hline Casos suspeitos & 9.242 \\
\hline
\end{tabular}

O panorama da ocupação dos leitos do Hospital Leonardo da Vinci (tabela 2) atualizado no dia 15 de abril de 2020, às 03:17 foi de $47 \%$ na clínica médica III, 64\% na clínica médica IV, 36\% na clínica médica V, $89 \%$ na UTI I, 100\% na UTI II e 100\% na UTI III [6].
Os indicadores hospitalares do estado apresentaram na última atualização do dia 01 de janeiro de 2020, a taxa de ocupação (\%) dos leitos (tabela 3), $83,86 \%$ HGCC, 83,93\% HGF, 83,57\% HGWA, 92,13\% HRN, 67,53\% HRSC, 59,55\% HSJ, 88,08\% HSM [6].

Tabela 2. Panorama da ocupação dos leitos - Hospital Leonardo da Vinci - Última atualização dia 15 de abril de 2020 às 03:17.

\begin{tabular}{|l|c|c|c|c|}
\hline \multicolumn{1}{|c|}{ Clínica/Unidade } & Leitos & Pacientes & Vagos & Taxa de ocupação (\%) \\
\hline CLÍNICA MÉDICA III & 36 & 17 & 19 & 47 \\
\hline CLÍNICA MÉDICA IV & 36 & 23 & 23 & 64 \\
\hline CLÍNICA MÉDICA V & 36 & 13 & 1 & 36 \\
\hline UTII & 9 & 8 & 0 & 100 \\
\hline UTI II & 7 & 7 & 0 & 100 \\
\hline UTI III & 12 & 12 & & 89 \\
\hline
\end{tabular}

Tabela 3. Taxa de ocupação dos leitos (\%) no Ceará, atualizado no dia 01 de janeiro de 2020. 


\begin{tabular}{|c|c|}
\hline HGCC & $83,86 \%$ \\
\hline HGF & $83,93 \%$ \\
\hline HGWA & $83,57 \%$ \\
\hline HRN & $92,13 \%$ \\
\hline HRSC & $67,53 \%$ \\
\hline HSJ & $59,55 \%$ \\
\hline HSM & $88,08 \%$ \\
\hline
\end{tabular}

Hospital Geral Dr. César Cals (HGCC), Hospital Geral de Fortaleza (HGF), Hospital Geral Dr. Waldemar Alcântara (HGWA), Hospital Regional Norte (HRN), Hospital Regional do Sertão Central (HRSC), Hospital São José (HSJ), Hospital de Saúde Mental (HSM).

\section{DISCUSSÃO}

O hospital Leonardo da Vinci, estruturado para o atendimento de pessoas afetadas pela infecção do novo coronavírus, dispõe de 108 leitos e 28 leitos de UTI. E adquirido no dia 15 de abril de 2020, o hospital Batista pela necessidade emergente de novos leitos, o segundo equipamento destinado a receber exclusivamente pacientes com covid-19, possui 131 novos leitos, incluindo 7 UTIs, e um hospital de campanha sendo construído no estádio Presidente Vargas. Outros equipamentos de saúde apresentam altas taxas de vagas já em ocupação desde janeiro, antes da chegada do vírus, por demandas de rotina. A maior incidência de internados são do sexo masculino $(57,5 \%)$ e entre ambos os sexos, acima de 45 anos. Com concentração do número de casos em Fortaleza, 59 internados e 1.794 casos confirmados da doença, seguido de Caucaia (39 casos), Maracanaú (35 casos) e Aquiraz (30 casos).

Os sintomas da covid-19 podem ser graves para grupos de risco, como idosos e portadores de condições crônicas. A maior atenção se volta a síndrome respiratória aguda, onde há necessidade do auxílio de respiradores devido a grave infecção do trato respiratório inferior. Por isso, a superlotação nas unidades de terapia intensiva [7].

A redução de investimentos no sistema único de saúde (SUS), pesquisa científica e a chegada do novo coronavírus poderão ser fatores ainda mais agravantes. Faz-se necessário para o combate o abastecimento de equipamentos de proteção individuais (EPI), descentralizar equipamentos com o objetivo de diagnóstico, respiradores para pacientes com sintomas graves, abertura de novos leitos com extrema urgência, investimentos em pesquisa, educação em saúde para conscientização da população sobre o impacto do distanciamento e isolamento social, afim de desacelerar esse colapso que já encontra-se em evidência.

\section{CONCLUSÃO}

Diante dos dados apresentados sobre a situação do estado do Ceará frente a pandemia da Covid-19, podese concluir que apresenta um cenário de preocupação diante de poucos leitos disponíveis, face de um possível colapso com a incidência dos casos mais graves da doença que necessitam de suporte adequado. Ressalta-se que o sistema público de saúde, continua atendendo todas as demandas costumeiras, e atualmente as advindas da síndrome respiratória aguda provocada pela covid-19, o que contribui sobremaneira para o caos que se evidencia.

\section{REFERÊNCIAS}

1. Boletim epidemiológico: Doenças crônicas não transmissíveis. Ceará, 2018 nov 22; 1-11. Disponível em: https://www.saude.ce.gov.br/wp-content/uploads/ sites/9/2018/06/boletim_epidemiologico_DCNT_22_ novembro_2019.pdf. Acesso em: 14 de abr. 2020.

2. IBGE - Instituto Brasileiro de Geografia e Estatística. Censo demográfico: Ceará, 2010. Disponível em: https://cidades.ibge.gov.br/brasil/ 
ce/pesquisa/32/28163. Acesso em: 14 abr. 2020.

3. Araujo-Filho JAB; Sawamura MVY; Costa AN; Cerri GG; Nomura $\mathrm{CH}$. Pneumonia por COVID-19: qual o papel da imagem no diagnóstico? J Bras Pneumol. 2020 abr;46(2). Disponível em: http://www.jornaldepneumologia.com.br/ detalhe_artigo.asp?id=3333. Acesso em: 15 abr. 2020.

4. Silva AAM. Sobre a possibilidade de interrupção da epidemiapelocoronavírus(COVID-19)combasenasmelhores evidências científicas disponíveis. Rev Bras Epidemiol, 2020 mar 16. Disponível em: http://www.scielo.br/scielo. php?script=sci_arttext\&pid=S1415-790X20200001001 00\&lng=pt\&nrm=iso\&tlng=pt. Acesso em: 15 abr. 2020.

5. Lana RM et al. Emergência do novo coronavírus (SARS-CoV-2) e o papel de uma vigilância nacional em saúde oportuna e efetiva. CSP, 2020 Mar;36(3). Disponível em: http://cadernos.ensp.fiocruz.br/csp/ artigo/999/emergncia-do-novo-coronavrus-sarscov-2-e-o-papel-de-uma-vigilncia-nacional-emsade-oportuna-e-efetiva. Acesso em: 15 abr. 2020.

6. Boletim epidemiológico novo coronavírus. Ceará, 2020 abr 14. Disponível em: https:// indicadores.integrasus.saude.ce.gov.br/indicadores/ indicadores-hospitalares. Acesso em: 15 abr. 2020.

7. NobreAFS; Sousa RCM; SantosMC; BarbagelataLS; Júnior EC; Lima DF et al. Primeira detecção de coronavírus humano associado à infecção respiratória aguda na Região Norte do Brasil. Rev Pan-Amaz Saúde, 2014 abr 4;5(2). Disponível em: http://scielo.iec.gov.br/scielo.php?script=sci_arttext\&p id=S2176-62232014000200005. Acesso em: 09 abr. 2020. 